\title{
PERANCANGAN APLIKASI PENENTUAN KUALITAS KELAPA MENGGUNAKAN METODE WEIGHTED PRODUCT (WP) BERBASIS WEB
}

\author{
Sulasih Wijayanti \\ Program Studi Sistem Informasi, Universitas Islam Indragiri \\ Email: Sulasihwijayanti1022@gmail.com (korespondensi)
}

\begin{abstract}
Plantation is one of the backbone of economy, Indragiri Hilir (Inhil), Riau. One of them is coconut, with the big potential of coconut, Indragiri Hilir made the coconut palm as superior product. Sometimes, there is lack of knowledge and information about the coconut quality. This research aimed to apply the weighted product (WP), an application of selecting the coconut quality, which can solve the problem for coconut seller in order to get the information.

Therefore, in order to know the price and quality of coconut by using the weighted product (WP) method, it has to use multiplication to connect attribute value, where the value must be raised first with the weight of the attribute in question.

By using the weighted product (WP) method of decision support, then implemented into a system that determines the level of importance in each criteria, they are; price and weight. The source of knowledge system is obtained by collecting data and information. This software is expected to help to determine the quality of coconut to the buyer of coconut and farmer.
\end{abstract}

Keywords: Selection Of Coconut Quality, Weighted Product (WP)

\begin{abstract}
Abstrak
Perkebunan merupakan salah satu tulang punggung perekonomian Kabupaten Indragiri Hilir (Inhil), Riau. Salah satu nya adalah kelapa, dengan potensi kelapa yang begitu besar ini, Indragiri Hilir menjadikan perkebunan kelapa dalam sebagai produk unggulan, Dengan potensi kelapa yang begitu besar terkadang kurangnya pengetahuan dan informasi akan kualitas kelapa yang akan dijual. tujuan penelitian ini untuk membangun sebuah aplikasi pemilihan kualitas kelapa menggunakan Metode Weighted Product (WP), yang dapat menyelesaikan permasalahan bagi pengguna yaitu calon penjual kelapa untuk mendapatkan informasi.

Maka dari itu untuk mengetahui harga dan kualitas kelapa dengan menggunakan metode weighted product merupakan metode penyelesaian dengan menggunakan perkalian untuk menghubungkan nilai atribut, dimana nilai harus dipangkatkan terlebih dahulu dengan bobot atribut yang bersangkutan.

Dengan menggunakan metode Weighted Product (WP) pada pendukung keputusan, kemudian diimplementasikan ke dalam sebuah sistem yang menentukan tingkat kepentingan pada setiap kriteria yaitu harga dan bobot. Sumber pengetahuan sistem di peroleh dengan mengumpulkan data-data dan informasi. Dengan adanya perangkat lunak ini diharapkan mampu membantu untuk menentukan kualitas kelapa kepada para pembeli kelapa dan petani
\end{abstract}

Kata kunci: pemilihan kualitas kelapa, Weighted Product (WP)

\section{PENDAhuluan}

Sektor perkebunan merupakan salah satu tulang punggung perekonomian Kabupaten Indragiri Hilir (Inhil), Riau. Berbagai komoditas tanaman perkebunan yang telah dikembangkan selama ini adalah kelapa lokal, kelapa hibrida, kelapa sawit, karet, kopi, coklat dan pinang dan juga sagu.Dari berbagai komoditas tersebut, kelapa lokal merupakan primadona. Inhil mempunyai 
$11,46 \%$ persen perkebunan kelapa dari total 3.742.921 luas perkebunan kelapa rakyat secara nasional (Data Direktorat Jenderal Perkebunan Tahun 2012). Dengan potensi kelapa yang begitu besar ini, tak membuat Pemerintah Kabupaten Indragiri Hilir menjadikan perkebunan kelapa dalam sebagai produk unggulan kabupaten, mencanangkan revitalisasi dan pelestariannya sebagai sumber utama perekonomian rakyat. Untuk itu tidak salah jika kita sebut, Kelapa Inhil merupakan Pusaka Provinsi Riau.Dengan potensi kelapa yang begitu besar ini Kabupaten Indragiri Hilir banyak banyak terdapat pula variasi harga kelapa di berbagai daerah kabupaten Indragiri Hilir. Sehingga memerlukan prosedur yang baku dalam menentukan kualitas kelapa dan hagra yang terbaik pula. Jika proses pengambilan keputusan harga kelapa dan kualitas kelapa dibantu oleh sebuah sistem pendukung keputusan yang terkomputerisasi diharapkan subyektifitas dalam pengambilan keputusan dapat dikuarangi berdasarkan kriteria-kriteria untuk harga kelapa sehingga harga kelapa dapat ditentukan dengan baik dan mempermudah dalam penentuan harga dan kualitas kelapa.

Berdasarkan masalah yang terjadi maka penelitian mengangkat permasalahan tersebut sebagai topik pada penelitian ini yang diberi judul "Aplikasi Penentuan Kualitas Kelapa Menggunakan Metode Weighted Product (WP) Berbasis Web". Dengan adanya sistem ini diharapkan dapat membantu dan memberikan informasi tentang kualitas dan harga terbaik yang sesuai bagi petani kelapa di Kabupaten Indragiri Hilir.

\subsection{Perumusan Masalah}

Berdasarkan latar belakang diatas maka dapat dirumuskan permasalah sebagai berikut:

1. Banyaknya Variasi kelapa sehingga petani dan pembeli kelapa perlu mempertimbangkan dalam menentukan kualitas dan harga kelapa yang sesuai.

2. Tidak adanya ketentuan dalam menentukan harga dan kualitas kelapa menyulitkan petani untuk menjual kelapa

3. Kurangnya informasi dalam menentukan kualitas kelapa yang baik sehingga petani selalu terfokus kepada penampung kelapa.

\subsection{Batasan Masalah}

Supaya tetap terfokus terhadap permasalahan dan tujuan penelitian, maka permasalahan dapat dibata sisebagai berikut:

1. Sistem Pendukung keputusan ini menggunakan metode weigted product.

2. Informasi yang dihasilkan berupa ktiteria kelapa yang masuk kategori layak jual dan harga yang sesuai

3. Aplikasi dikembangkan dengan bahasa pemograman PHP dan HTML dengan menggunakan interface Macromedia Dreamweaver Versi 8.

\subsection{Tujuan Penelitian}

Adapun tujuan penelitian adalah :

1. Untuk membuat sistem yang baru sehingga mengefesienkan waktu dalam penjualan kelapa dengan ketentuan dan kriteria tertentu.

2. Memberikan gambaran kepada petani tentang kelapa yang termasuk dalam kriteria layak jual.

3. Memberikan solusi dalam menentukan dan mempermudah penjualan.

4. Membuat aplikasi tentang kualitas kelapa mengunakan metode Weighted Product berbasis Web

\subsection{Manfaat Penelitian}

Diharapkan aplikasi ini mampu membantu masyarakat untuk lebih memudahkan dalam mengakses informasi kualitas dan harga kelapa juga dapat memudahkan menentukan pemasaran kelapa.

\subsection{Metode Penelitian}

Metode penelitian yang digunakan dalam penulisan tugas akhir ini adalah sebagai berikut :

\subsubsection{Metode Pengumpulan Data}

Pengumpulan data adalah berbagai cara yang digunakan untuk mengumpulkan data, menghimpun, mengambil, atau menjaring data penelitian. Kita mengenal metode observasi, wawancara, angket, dll. Pertimbangan utama dalam memilih metode adalah kemampuan cara yang dipilih dalam menggali informasi. Kadang hanya diperlukan satu cara. Namun, kadang cara tunggal dinilai kurang mampu menjaring data secara lengkap, sehingga dibutuhkan metode lain sebagai metode sekunder.

1. Studi Lapangan

Yaitu penelitian yang dilakukan dengan mendatangi langsung tempat penelitian. Adapun teknik yang di gunakan peneliti dalam pengumpulan data adalah :

a. Observasi

Yaitu cara yang digunakan dengan mendatangi tempat penelitian secara 
langsung dan sejauh mana keterlibatan peneliti/pengumpul data dalam event (kejadian) yang diamati. Dimana seorang peneliti bisa menjadi anggota suatu kelompok atau organisasi tertentu dan mengamatinya serta menghimpun data darinya atau cara lainnya yaitu peneliti tidak berada di dalam atau melakukan keterlibatan dalam kegiatan yang diamati, dengan kata lain hanya mendapat sebuah data tanpa ikut berpartisipasi.

b. Wawancara

Penulis melakukan wawancara langsung dengan narasumber untuk mengumpulkan data atau informasi yang dapat memberikan gambaran tentang sistem yang sedang berjalan dan melakukan analisis kebutuhan sistem berdasarkan data atau informasi yang diperoleh.

c. Kuisioner

Kuisioner merupakan metode pengumpulan data dengan cara polling dan survei yang melibatkan populasi yang luas. Kuisioner bisa berupa pertanyaan-pertanyaan dengan sejumlah opsi yang telah ditentukan dan responden diminta untuk menandai opsi yang paling sesuai.

2. Literatur (Kepustakaan)

Penelitian dilakukan dengan mempelajari buku-buku yang terdapat di perpustakaan juga melalui internet dengan sumber yang dapat dipercaya dengan maksud untuk memperoleh data yang dapat digunakan penyusun sebagai dasar perbandingan dalam pembahasan dan pengertian dasar teori yang dibutuhkan dalam penyusunan penelitian ini.

\subsubsection{Metode Pengembangan Sistem}

Pada penelitian ini, pengembangan sistem menggunakan model Prototype dimana seorang pengembang dan pengguna dapat saling berinteraksi selama proses pembuatan sistem, bertemu dan mendefinisikan objektik keseluruhan dari perangkat lunak, mengidentifikasi segala kebutuhan yang diketahui dan area garis besar dimana definisi lebih jauh merupakan keharusan dilakukan perancangan. Dan dalam pengambilan keputusan menggunakan metode "Weighted Product". Metode ini lebih efisien dibandingkan metode lain yang termasuk dalam penyelesaian masalah MADM (Multi Attibute Decision
Making). Alasannya karena waktu yang dibutuhkan dalam perhitungan lebih singkat. $\mathrm{Hal}$ ini diperkuat dengan beberapa referensi yang digunakan.

\section{TINJAUAN PUSTAKA}

\subsection{Konsep sistem pendukung keputusan}

Pada dasarnya pengambilan keputusan adalah suatu pendekatan sistematis pada hakekat suatu masalah, pengumpulan fakta-fakta, penentuan yang matang dari alternatif yang dihadapi, dan pengambilan tindakan yang menurut perhitungan merupakan tindakan yang paling tepat.

Pada sisi lain, pembuat keputusan kerap kali dihadapkan pada kerumitan dan lingkup pengambilan keputusan dengan data yang begitu banyak. Untuk kepentingan itu, sebagian besar pembuat keputusan dengan mempertimbangkan rasio manfaat/biaya, dihadapkan pada suatu keharusan untuk mengandalkan seperangkat sistem yang mampu memecahkan masalah secara efisien dan efektif (Suryadi \& M. Ali Ramdhani, 2002).

\subsection{Sistim}

Ada beberapa pengertian sistem menurut beberapa pakar sistem informasi, antara lain:

1. Sistem merupakan kumpulan elemen yang saling berkaitan yang bertanggung jawab memproses masukan (input) sehingga menghasilkan keluaran /output(Kusrini, 2007).

2. Sistem terdiri dari komponenkomponen yang saling berkaitan dan bekerja sama untuk mencapai suatu tujuan (Suryantara, 2014: 2).

2. Sistem (system) adalah sekelompok elemen-elemen yang terintegrasi dengan tujuan yang sama untuk mencapai tujuan. Setiap sistem tidak memiliki kombinasi elemen-elemen yang sama. Secara garis besar elemenelemen dari sistem dapat berupa tujuan, mekanisme kontrol, input, output, dan transformasi (McLeod dalam Yakub dan Hermanto, 2010: 1).

\subsection{Keputusan}

Keputusan merupakan kegiatan memilih suatu strategi atau tindakan dalam pemecahan masalah tersebut. Tindakan memilih strategi atau aksi yang diyakini manajer akan memberikan solusi terbaik atas sesuatu itu disebut pengambilan keputusan.

Tujuan dari keputusan adalah untuk mencapai target atau aksi tertentu yang harus dilakukan.

Kriteria atau ciri-ciri dari keputusan 
adalah:

1. Banyak pilihan/alternatif

2. Ada kendala atau syarat

3. Mengikuti suatu pola/model tingkah laku, baik yang terstruktur maupun tidak terstruktur

4. Banyak input/variabel

5. Ada faktor resiko

6. Dibutuhkan kecepatan, ketepatan, dan keakuratan (Kusrini, 2007: 7).

\subsection{Sistem Pendukung Keputusan}

Sistem pendukung keputusan (SPK) biasanya dibangun untuk mendukung solusi atas suatu masalah atau suatu peluang.Aplikasi sistem pendukung keputusan digunakan dalam pengambilan keputusan. Aplikasi system pendukung keputusan menggunakan CBIS (Computer Based Information support) yang fleksibel, nteraktif, dam dapat diataptasi, yang dikembangkan untuk mendukung solusi atas masalah manajemen spesifikasi yang tidak terstruktur (Dicky Nofriansyah, S.Kom, M.Kom. 2014).

Menurut Bonczek, dkk,(1980) dalam buku Decision Support System And Intelligent System (Turban, 2015:137) mendefinisikan system pendukung keputusan sebagai system berbasis computer yang terdiri dari tiga komponen yang saling berinteraksi, Sistem Bahasa (mekanisme untuk memberikan kuputusan lain), Sistem Pengetahuan (responsistori pengetahuan dominan masalahyang ada pada system pendukung keputusan atau sebagai data atau sebagai prosedur), dan Sistem Pemrosesan Masalah (hubungan antara dua komponen lainnya, terdiri dari satu atau lebih kapasisteas manipulasi masalah umum yang diperlukan untuk pembelian keputusan).

\subsection{Weighted Product (WP)}

Metode WP (Weighted Product) merupakan salah satu metode didalam penentuan sebuah keputusan dengan cara perkalian untuk menghubungkan ranting attribut, dimana ranting attribute setiap attribute harus dipangkatkan dulu dengan bobot attribute yang bersangkutan. Proses tersebut sdama halnya dengan proses normalisasi.

Rumus-rumus dalam metode Weighted Product dapat ditulis sebagai berikut:

Rumus perhitungan Bobot:

$$
W J=\frac{W j}{\sum W_{j}}
$$

Ket :

$$
\begin{aligned}
\mathrm{W} & =\text { Bobot Kriteria } \\
\mathrm{j} & =\text { Kriteria }
\end{aligned}
$$

Rumus WP (WeigtedProduct):

$$
S_{1}=\prod_{j=1}^{n} X_{i j}^{w 1}
$$

Ket :

$$
\begin{aligned}
\mathrm{S}= & \text { Preferensi alternative di } \\
& \text { anologikan sebagai vektor } \mathrm{S} \\
\mathrm{X}= & \text { Nilaikriteria } \\
\mathrm{W}= & \text { Bobotkriteria / Subkriteria } \\
\mathrm{i}= & \text { Alternatif (dimana } \mathrm{i}=1,2, \ldots . \mathrm{n}) \\
\mathrm{j}= & \text { Kriteria } \\
\mathrm{n}= & \text { Banyaknya kriteria }
\end{aligned}
$$

Perangkingan WP(WeigtedProduct):

$$
V_{1}=\frac{\prod_{j}^{n}=1^{x_{i j}^{w j}}}{\prod_{j}^{n}=1\left(^{x_{j}^{n}}\right)}
$$

$$
\begin{aligned}
& \mathrm{V}=\underset{\text { preverensi alternatif dianologi }}{\text { vektor } \mathrm{V}} \\
& \mathrm{X}
\end{aligned}
$$$$
X=\text { nilaiKriteria }
$$

$\mathrm{W}=$ Bobotkriteria / Subkriteria

$\mathrm{i}=$ Alternatif (dimana $\mathrm{i}=1,2, \ldots . \mathrm{n})$

$\mathrm{j}=$ Kriteria

$\mathrm{n}=$ Banyaknya kriteria

Metode Weighted Product menggunakan perkalian untuk menghubungkan rating atribut, dimana rating setiap atribut harus dipangkatkan dulu dengan bobot atribut yang bersangkutan. (Dicky Nofriansyah, 2014).

\section{ANALISA DAN PERANCANGAN SISTEM}

Metode penelitian merupakan gambaran pendekatan, tipe, jenis, dan desain penelitian. Dalam sub bab ini akan dibahas mengenai bagan alur (Flowchart) metode penelitian 


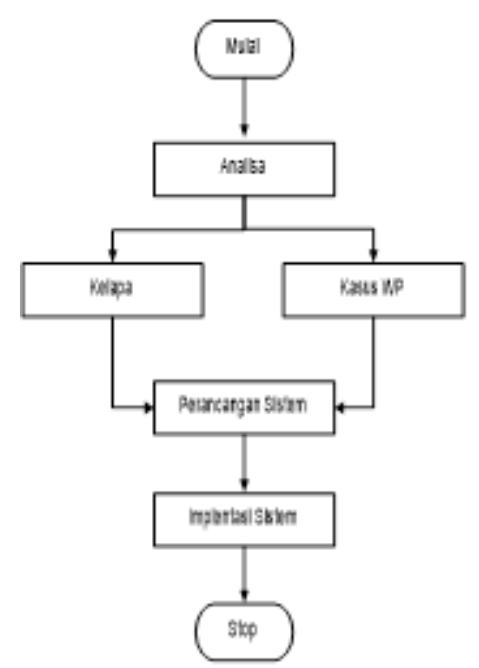

Gambar 1. Flow chart

Sistem Penunjang keputusan kualitas kelapa ini adalah suatu sistem yang digunakan untuk mengklasifikasikan pola pemilihan kualitas kelapa.Proses penentuan kualitas kelapa tersebut berdasarkan berat kelapa. Analisa sistem dan perinsipnya adalah mempelajari sistem dengan melakukan penelitian dan pengamatan terhadap unit-unit kerja yang terlibatdalam proses penentuan kualitas kelapa. Hal ini ditunjukkan untuk mengetahui secara jelas dan terinci proses penentuan kualitas kelapa, yang selama ini menjadi permasalahan para petani serta untuk mengevaluasi permasalahan, hambatanhambatan yang terjadi dan kebutuhan yang diharapkan sehingga akan dapat diusulkan suatu pengembangan sistem informasi yang baru.

Untuk pemecahan masalah dalam suatu sistem maka diperlukan adanya analisis sistem, Sistem penunjang keputusan mampu menyelesikan masalah penentuan kualitas kelapa yang di aplikasikan kedalam bentuk perangkat lunak sehingga dapat menghemat waktu dan biaya.

\section{Penerapan Metode Weighted Product (WP)}

Dalam membangun aplikasi penentuan kualitas kelapa dengan metode Weighted Product diperlukan data kriteria, dan data bobot. Untuk pemberian nilai bobot tergantung pada pengambil keputusan. Sebagai contoh implementasi metode Weighted Product secara manual. Berikut ini data-data yang dibutuhkan untuk pengambilan keputusan

1. Data kelapa

Tabel 1 Data Kelapa

\begin{tabular}{|c|c|c|} 
No. & $\begin{array}{c}\text { Kualitas } \\
\text { Kelapa }\end{array}$ & Berat \\
\hline
\end{tabular}

\begin{tabular}{|l|c|l|}
\hline 1 & Kelapa A+ & $1,5 \mathrm{Kg}$ keatas \\
\hline 2 & Kelapa A & $1,2 \mathrm{Kg}-1,5 \mathrm{Kg}$ \\
\hline 3 & Kelapa B & 0,9 Ons $-1,2 \mathrm{Kg}$ \\
\hline 4 & Kelapa C & 0,6 Ons $-0,9$ Ons \\
\hline
\end{tabular}

Tabel 2 Daftar Harga

\begin{tabular}{|c|c|}
\hline NO. & \multicolumn{1}{|c|}{ Harga Kelapa } \\
\hline 1 & Rp. 6.000 \\
\hline 2 & Rp. 5.000 \\
\hline 3 & Rp. 4.000 \\
\hline 4 & Rp. 3.000 \\
\hline
\end{tabular}

2. Metode WP untuk menentukan kualitas kelapa kelapa terdapat 4 artenatif yaitu :

$\mathrm{A} 1=$ Rp. 6.000

$A 2=$ Rp. 5.000

$A 3=$ Rp. 4.000

$\mathrm{A} 4=$ Rp. 3.000

Kriteria yang digunakan sebagai acuan yaitu :

$\mathrm{C} 1=1,5 \mathrm{Kg}$ keatas

$\mathrm{C} 2=1,2 \mathrm{Kg}-1,5 \mathrm{Kg}$

$\mathrm{C} 3=0,9$ Ons $-1,2 \mathrm{Kg}$

$\mathrm{C} 4=0,6$ Ons - 0,9 Ons

Pengambilan keputusan memberikan bobot preferensi sebagai berikut :

$W=(5,4,3,2)$

Tingkat kepentingan dan bobot setiap kriteria, juga dinilai dengan 1 sampai 5, yaitu:

Tabel 3 Bobot Kriteria

\begin{tabular}{|c|c|c|c|}
\hline Nilai & Bobot & Keterangan & $\begin{array}{c}\text { Bobot } \\
\text { Kriteria }\end{array}$ \\
\hline 5 & $50 \%$ & Terbaik & Tertinggi \\
\hline 4 & $30 \%$ & Baik & \multirow{1}{*}{} \\
\hline 3 & $15 \%$ & Cukup & \\
\hline 2 & $10 \%$ & sedang & \multirow{2}{*}{ Terendah } \\
\hline 1 & $5 \%$ & kurang & \multicolumn{1}{|c}{} \\
\cline { 1 - 3 }
\end{tabular}

Tabel 4 Bobot untuk penilaian

\begin{tabular}{|c|c|c|}
\hline Nilai & Bobot & Keterangan \\
\hline $80-100$ & 5 & Terbaik \\
\hline $60-79$ & 4 & Baik \\
\hline $40-59$ & 3 & Cukup \\
\hline $20-39$ & 2 & sedang \\
\hline $0-9$ & 1 & kurang \\
\hline
\end{tabular}

Tabel 5 Nilai Alternatif

\begin{tabular}{|c|c|c|c|c|}
\hline \multirow{2}{*}{$\begin{array}{c}\text { Altern } \\
\text { atif }\end{array}$} & \multicolumn{4}{|c|}{ Kriteria } \\
\hline & $\mathrm{C} 1$ & $\mathrm{C} 2$ & C3 & $\mathrm{C} 4$ \\
\hline $\begin{array}{c}\text { Kelapa } \\
\mathrm{A}+\end{array}$ & $\begin{array}{l}1,5 \mathrm{Kg} \\
\text { keatas }\end{array}$ & $\begin{array}{l}1,2 \mathrm{Kg}- \\
1,5 \mathrm{Kg}\end{array}$ & $\begin{array}{l}0,9 \text { Ons } \\
-1,2 \mathrm{Kg}\end{array}$ & $\begin{array}{l}0,6 \text { Ons } \\
-0,9 \\
\text { Ons }\end{array}$ \\
\hline $\begin{array}{c}\text { Kelapa } \\
\text { A }\end{array}$ & $\begin{array}{l}1,5 \mathrm{Kg} \\
\text { keatas }\end{array}$ & $\begin{array}{l}1,2 \mathrm{Kg} \mathrm{-} \\
1,5 \mathrm{Kg}\end{array}$ & $\begin{array}{l}0,9 \text { Ons } \\
-1,2 \mathrm{Kg}\end{array}$ & $\begin{array}{l}0,6 \text { Ons } \\
-0,9 \\
\text { Ons }\end{array}$ \\
\hline $\begin{array}{c}\text { Kelapa } \\
\text { B }\end{array}$ & $\begin{array}{l}1,5 \mathrm{Kg} \\
\text { keatas }\end{array}$ & $\begin{array}{l}1,2 \mathrm{Kg}- \\
1,5 \mathrm{Kg}\end{array}$ & $\begin{array}{l}0,9 \text { Ons } \\
-1,2 \mathrm{Kg}\end{array}$ & $\begin{array}{l}0,6 \text { Ons } \\
-0,9 \\
\text { Ons }\end{array}$ \\
\hline Kelapa & $1,5 \mathrm{Kg}$ & $1,2 \mathrm{Kg} \mathrm{-}$ & 0,9 Ons & 0,6 Ons \\
\hline
\end{tabular}




\begin{tabular}{|l|l|l|l|l|}
\hline $\mathrm{C}$ & keatas & $1,5 \mathrm{Kg}$ & $-1,2 \mathrm{Kg}$ & $\begin{array}{l}-0,9 \\
\text { Ons }\end{array}$ \\
\hline
\end{tabular}

Tabel 6 Bobot Kriteria Setiap Kualitas Kelapa

\begin{tabular}{|c|c|c|c|c|}
\hline \multirow{2}{*}{$\begin{array}{c}\text { Altern } \\
\text { atif }\end{array}$} & \multicolumn{4}{|c|}{ Kriteria } \\
\cline { 2 - 5 } & C1 & C2 & C3 & C4 \\
\hline $\begin{array}{c}\text { Kelapa } \\
\text { A+ }\end{array}$ & 90 & 79 & 59 & 39 \\
\hline $\begin{array}{c}\text { Kelapa } \\
\text { A }\end{array}$ & 87 & 70 & 50 & 35 \\
\hline $\begin{array}{c}\text { Kelapa } \\
\text { B }\end{array}$ & 85 & 59 & 48 & 30 \\
\hline $\begin{array}{c}\text { Kelapa } \\
\text { C }\end{array}$ & 80 & 39 & 40 & 25 \\
\hline
\end{tabular}

Normalisasi Bobot dengan Rumus

$W j=\frac{W j}{\sum W j}$

$$
\begin{aligned}
& W 1=\frac{5}{5+4+3+2}=0.3571 \\
& W 2=\frac{4}{5+4+3+2}=0.2857 \\
& W 3=\frac{3}{5+4+3+2}=0.2143 \\
& W 4=\frac{2}{5+4+3+2}=0.1429
\end{aligned}
$$

Langkah selanjutnya menghitung nilai Vektor S:

$$
S_{i}=\prod_{j=1}^{n}=X_{i j}{ }^{W_{j}}
$$

Alternatif Kelapa A+

$\mathrm{S} 1=\left(90^{0,3571}\right)\left(79^{0.2857}\right)\left(59^{0.2143}\right)\left(39^{0.1429}\right)=70.29$

Alternatif Kelapa A

$\mathrm{S} 2=\left(87^{0,3571}\right)\left(70^{0.2857}\right)\left(50^{0.2143}\right)\left(35^{0.1429}\right)=63.75$

Alternatif Kelapa B

S3 $=\left(85^{0,3571}\right)\left(59^{0.2857}\right)\left(48^{0.2143}\right)\left(30^{0.1429}\right)=58.39$

Alternatif Kelapa C

S4 $=\left(80^{0,3571}\right)\left(39^{0.2857}\right)\left(40^{0.2143}\right)\left(25^{0.1429}\right)=47.56$

Menghitung Preferensi (Vi) untuk perangkingan :

$$
V_{i}=\frac{\Pi_{j}^{n}={ }_{1} X_{i j}{ }^{W_{j}}}{\Pi_{j}^{n}={ }_{1} X_{i j}{ }^{W_{j}}}
$$

Alternatif Kelapa A+
$V 1=70.29 /(70.29+6375+58.39+47.56)$ $=0.2928792$

Alternatif Kelapa A

$V 2=6375 /(70.29+6375+58.39+47.56)$ $=0.2656470$

Alternatif Kelapa B

$V 3=85.39 /(70.29+6375+58.39+47.56)=$ 0.2432885

AlternatifKelapa C

$V 4=47.56 /(70.29+6375+58.39+47.56)=0.1981853$

Setelah mendapatkan nilai akhir Vi maka dapat dilakukan peringkingan berdasarkan hasil akhir sebagai berikut :

1. Rangking I Kriteria Kelapa A+ Preferensi V1 dengan nilaio, 2928792

2. Rangking II Kriteria Kelapa A Preferensi V2 dengan nilai0, 02656470

3. Rangking III Kriteria Kelapa BPreferensi V3 dengan nilaio. 2432885

4. Rangking IV Kriteria Kelapa CPreferensi V4 dengan nilaio, 1981853

4. IMPLEMENTASI DAN SISTEM

Pada uji coba sistem dan program akan dilakukan beberapa sampel yaitu administrator dapat login dengan user dan pass word yang sudah di tentukan.Bagian administrator berperan penting dalam manajemen informasi pada aplikasi web sistem pendukung keputusan ini. Administrator dapat melakukan proses login untuk masuk ke halaman utama admin serta memiliki hak penuh dalam manipulasi data, dapat memasukkan beberapa data nilai, kriteria, alternative, bobot dan rangking. Selanjutnya sistem akan menyimpan data kedalam database. 


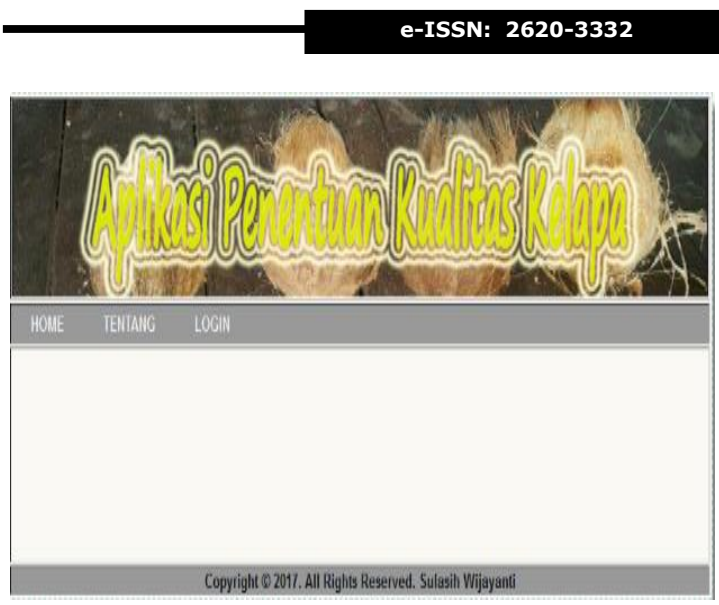

Gambar 1 Halaman Utama

Pada gambar 1 merupakan halaman awal yang akan dimasuki mengakses aplikasi penentuan kualitas kelapa.

\begin{tabular}{l} 
Member Area \\
Username \\
Passworname \\
Password \\
Login \\
\hline
\end{tabular}

Gambar 2 Form Login Administrator

Pada gambar 2 sebelum masuk ke sistem maka user login dahulu dengan memasukkan username dan password.

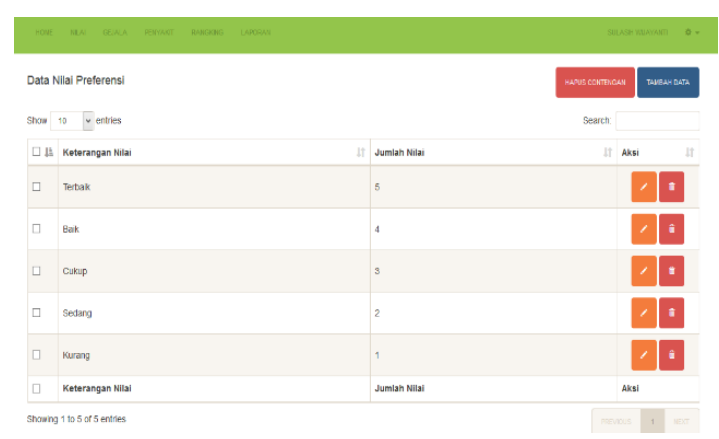

Gambar 3 Halaman Nilai

Pada gambar 3 halaman nilai kualitas kelapa

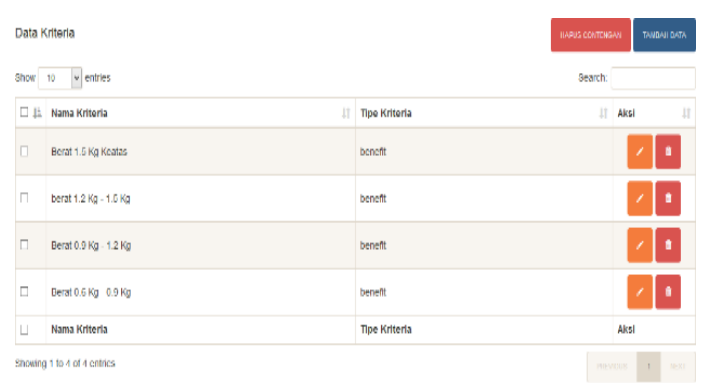

Gambar 4 Halaman Input Kriteria

Pada gambar 4.4 halaman kriteria kualitas kelapa

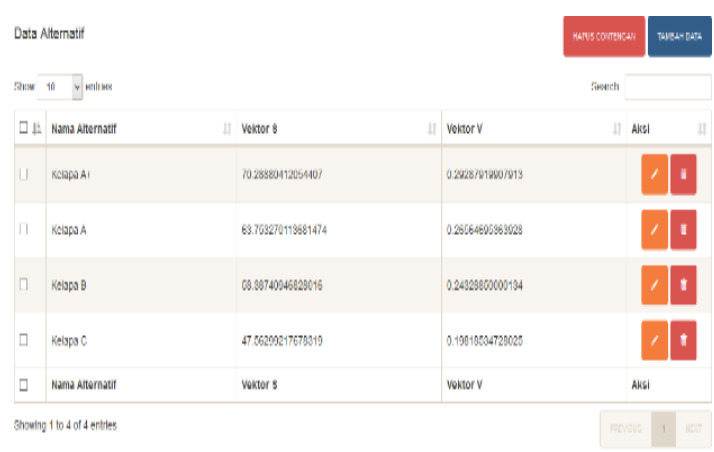

Gambar 5 Halaman input alternatif Pada gambar 5 halaman kriteria alternatif

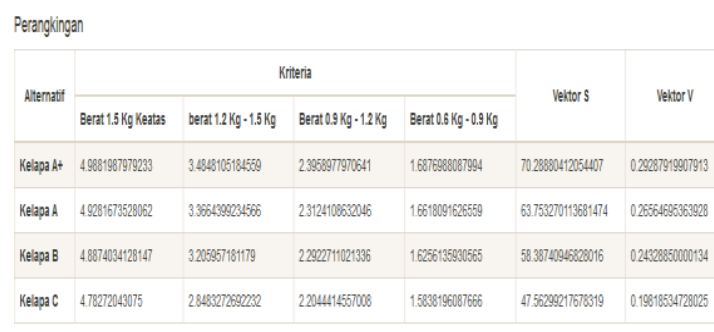

02017

\section{Gambar 6 Halaman hasil Perangkingan}

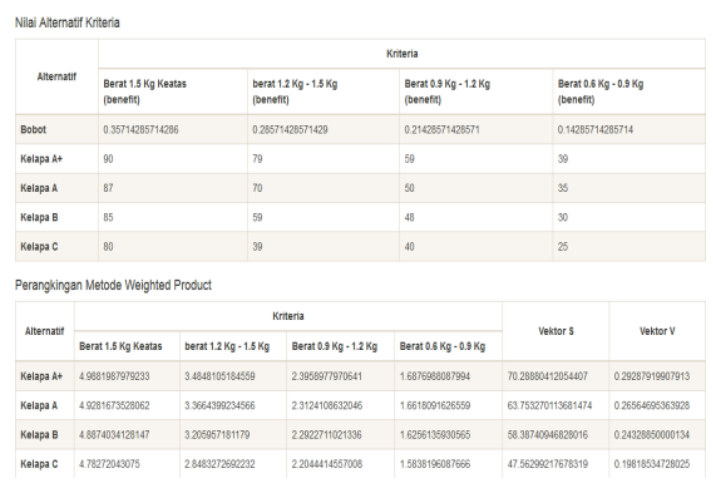

Gambar 7 Halaman hasil laporan Perangkingan 


\section{KESIMPULAN DAN SARAN}

\subsection{Simpulan}

Berdasarkan hasil pembahasan teori pada perancangan aplikasi penentuan kualitas kelapa menggunakan metode Weigthted Product dapat disimpulkan sebagai berikut:

1. Sistem pendukung keputusan dapat memberikan keputusan yang baik dalam menentukan kualitas kelapa terbaik.

2. Sistem Pendukung keputusan kualitas kelapa ini mampu memberikan solusi untuk menentukan harga yang sesuai dengan kriteria kelapa.

3. Sistem pendukung keputusan penentuan kualitas kelapa yang berbasis web dapat di akses oleh semua orang yang ingin berkonsultasi karena sistem yang dijalankan berupa aplikasi web.

4. Sistem yang berbasis web dengan metode Weigthted Product mampu menganalisa kriteria dana alternatif dengan pembobotan dan dapat memberikan informasi solusi

\subsection{Saran}

Adapun saran-saran dari penulis untuk penggunaan aplikasi penentuan kualitas kelapa ini dapat diperhatikan sebagai berikut:

1. Dalam menggunakan website ini agar dapat diakses dengan cepat disarankan menggunakan koneksi internet yang memadai.

2. Bagi admin dapat memeriksa database tidak valid dan disarankan dapat menghapusnya dari database agar tidak terjadi spam.

3. Bagi admin dalam pemeliharaan database agar selalu memperhatikan ruang penyimpanan.Penggunaan ruang penyimpanan sangat disarankan hanya untuk data yang valid guna menghemat ruang penyimpanan yang mempercepat proses sistem.

4. Aplikasi ini nantinya dapat dikembangkan sehingga akan tampil lebih baik dengan sistem ini.

\section{DAFTAR PUSTAKA}

[1] Bonnie Soeherman. (2008). Designing Information SystemBudidaya Dan Pasca Panen. Yogyakarta:

[2] Dicky Nofriansyah, (2015) Konsep Data Mining vs Sistem Pendukung Keputusan. Yogyakarta
[3] Kusrini, M. (2007). Konsep dan Aplikasi Sistem Pendukung Keputusan. Yogyakarta: Andi Yogyakarta.

[4] Nofriansyah, Dicky S.Kom., M.Kom.(2015) Konsep Data Mining vs Sistem Pendukung Keputusan. Yogyakarta 